\title{
STUDIES OF THE RETICULOENDOTHELIAL SYSTEM (RES). I. MEASUREMENT OF THE PHAGOCYTIC CAPACITY OF THE RES IN MAN AND DOG*
}

\author{
By MASAHIRO IIO † AND HENRY N. WAGNER, JR., WITH THE TECH NICAL ASSISTANCE OF \\ URSULA SCHEFFEL AND BARBARA JABBOUR \\ (From the Division of Nuclear Medicine, The Johns Hopkins Medical Institutions, \\ Baltimore, $M d$.)
}

(Submitted for publication June 22, 1962; accepted November 29, 1962)

In 1884, Metchnikoff (1) presented his studies of phagocytosis and concluded that the process was a general reaction that removed particulate matter from the circulation. Highly mobile cells, the polymorphonuclear leukocytes, were observed to ingest microorganisms and other particulate matter, such as pus, corpuscular elements of extravasated blood, and foreign cells. In addition to these circulating phagocytes, or microphages, certain "reticulum" cells lining the blood and lymph spaces were observed to engulf circulating particulate matter. These fixed phagocytes were designated subsequently by Aschoff (2) as the reticuloendothelial system (RES), comprising the Kupffer cells of the liver, cells lining the sinuses of the spleen, lymph nodes, and bone marrow, and endothelial cells of various other organs.

To examine phagocytosis in experimental animals, one may use colloidal particles such as carbon, thorium dioxide (Thorotrast), saccharated iron oxide, and more recently, radioactive chromic phosphate, colloidal gold, or colloidal silver. Although they have yielded important information, studies with these inorganic colloidal substances have been of limited value in the study of human disease. Because the body cannot metabolize these particles, they remain in the RES almost indefinitely, and only trace quantities can be administered safely to human subjects. Since the rate of removal of trace quantities of particles from the circulation depends primarily on the blood flow to reticuloendothelial cells, the greatest usefulness of previously available colloidal particles has been in the measurement of liver blood flow.

* Aided by grant no. H-6454, U. S. Public Health Service.

$\dagger$ U. S. Public Health Service trainee.
In 1955, Benacerraf and associates (3) introduced the use of aggregates of human serum proteins labeled with radioiodine as a type of particulate matter that offered certain advantages in the study of phagocytosis. Macromolecular albumin aggregates are metabolized after removal from the circulation, as evidenced by the prompt reappearance of the radioactive iodine label (as free iodide) in the blood. This makes it feasible to administer large quantities of this material and derive information about the phagocytic capacity of the RES not obtainable by measurement of the clearance of minute quantities of nonmetabolizable materials.

The purpose of this report is to describe the method of preparation of the albumin particles and present the results of experiments which indicate that the aggregated albumin particles, labeled with radioactive iodine, may be safely used to measure the phagocytic capacity of the RES in man.

\section{MATERIALS AND METHODS}

The procedure used in this laboratory to prepare aggregated albumin was a modification of that described by Benacerraf and associates in 1955 (4). The method was based on the work of Taplin, Griswold, and Dore at the University of California (5) and Stern of the Squibb Laboratories (6). To insure sterility without terminal filtration, the entire procedure was conducted under rigidly aseptic conditions.

Salt-poor human serum albumin ${ }^{1}$ was diluted in $0.9 \%$ sodium chloride solution to reduce the concentration from 25 to $3 \%$. After alkalinization to $\mathrm{pH} 10.0$ with $0.2 \mathrm{~N}$ sodium hydroxide, optical density at a wave-length of $525 \mathrm{~m} \mu$ was measured in a Beckman spectrophotometer. The optical densities of various lots of albumin at this stage of preparation ranged from 0.031 to 0.047 . The alkaline solution was placed in a water-bath at $70^{\circ} \mathrm{C}$ and shaken continuously at a rate of 100 times per minute for

\footnotetext{
1 Produced by Squibb Laboratories.
} 


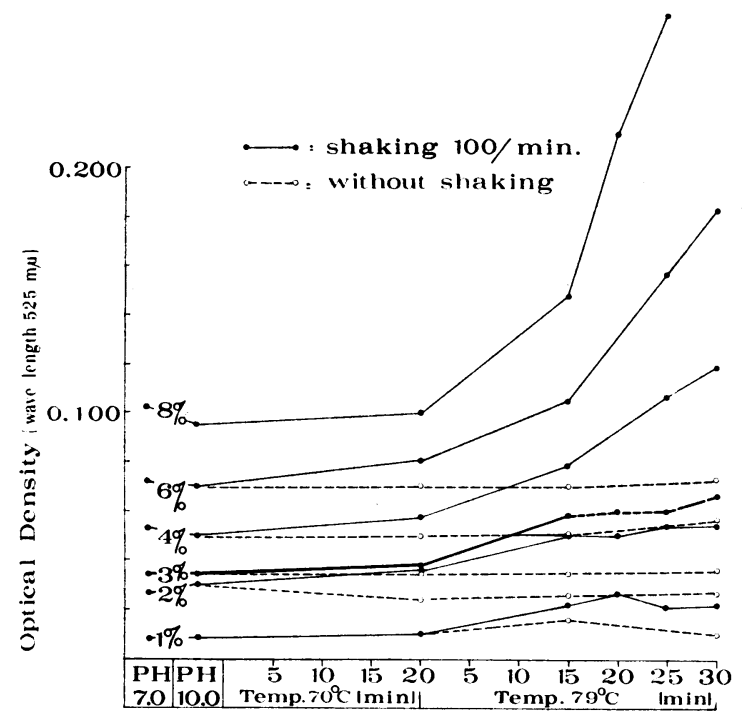

Fig. 1. Changes in optical Density During the PREPARATION OF AGGREGATED ALBUMIN. Various concentrations of albumin were used, both with and without shaking.

20 minutes with a Dubnoff shaker. This was followed immediately by shaking for an additional 15 minutes at $79^{\circ} \mathrm{C}$. The preparation was then cooled with running tap water, and its optical density was again determined. This was increased $0.026 \pm 0.005$ units (mean $\pm 1 \mathrm{SD}$ ) above the initial value.

Material to be used as nonradioactive aggregated albumin, i.e., carrier, was adjusted to $\mathrm{pH} 7.5$ with $0.2 \mathrm{~N}$ hydrochloric acid and stored at $4^{\circ} \mathrm{C}$, after sterility and pyrogen testing.

Material to be labeled with radioactive iodine was subjected to additional treatment. After the period of shaking at $79^{\circ} \mathrm{C}$, the albumin solution was brought to $\mathrm{pH} 5.0$ with $0.2 \mathrm{~N}$ hydrochloric acid with resulting precipitation of the protein. After centrifugation at 3,000 rpm for 20 minutes, the supernatant fluid was decanted and replaced by an equal volume of $0.1 \mathrm{~N}$ sodium bicarbonate. After storage overnight at $4^{\circ} \mathrm{C}$, the precipitate was found to be almost completely redissolved. The resultant slightly opalescent solution was then labeled with $I^{131}(6)$, the excess radioactive iodide being removed by passage of the final material through the anion exchange resin Amberlite IRA-400, chloride form. Prior to use, the labeled material was sterilized by Seitz filtration. The flocculation and filtration reduced the protein concentration from 3 to approximately $2 \%$.

Discussion of the method of preparation of aggregated albumin. Standardized agitation of the bottles containing alkalinized albumin was of great importance as evidenced by the fact that the optical density remained unchanged throughout the procedure if shaking was omitted.

The choice of an initial concentration of $3 \%$ was based upon studies of various concentrations of serum albumin, the results of which are shown in Figure 1 and Table I.
TABLE I

Mean molecular weight and optical density of colloidal albumin

\begin{tabular}{cccc}
\hline $\begin{array}{c}\text { Concen- } \\
\text { tration of } \\
\text { original } \\
\text { albumin } \\
\text { solution }\end{array}$ & $\begin{array}{c}\text { Molecular } \\
\text { weight of } \\
\text { final particle* }\end{array}$ & $\begin{array}{c}\text { Aggregated } \\
\text { albumin } \\
\text { molecules }\end{array}$ & $\begin{array}{c}\text { Change in } \\
\text { optical } \\
\text { densityt }\end{array}$ \\
\hline$\%$ & & $n o$. & \\
1 & 639,000 & 9 & +0.009 \\
3 & 787,000 & 11 & +0.024 \\
\hline
\end{tabular}

* Light scattering method.

$\uparrow$ Spectrophotometric method.

When concentrations of 4,6 , and $8 \%$ were used, the colloidal aggregates became progressively larger, as indicated by the rapid increase in optical density. These more highly concentrated solutions eventually resulted in unusable gels. When the $3 \%$ albumin solution was used, the mean molecular weight of the final colloid, measured by the light scattering method, indicated that an average of 11 albumin molecules had aggregrated, although the size of the particles was quite variable. Although the $1 \%$ albumin solution yielded a colloid whose mean molecular weight indicated that only slightly fewer molecules had polymerized, the $3 \%$ solution possessed the additional advantage of permitting injection of a larger amount of material in a given volume.

Reproducibility in the preparation of aggregated albumin. Previous studies in which colloids were used to measure liver blood flow have been plagued by poor reproducibility in the physiological behavior of different lots of material. Although the use of aggregated albumin is not without difficulties, careful attention to detail in its preparation (controlling the $\mathrm{pH}$, temperature, and amount of agitation, and monitoring the change in optical density) gives a high degree of uniformity. During a period of 8 months, we prepared 12 lots of aggregated carrier albumin with consistent results. During the same period we used 9 lots of $\mathrm{I}^{181}$-labeled aggregated albumin prepared by the Squibb Laboratories. ${ }^{2}$ The first shipment, lot DN-4, was used in all studies in dogs and in the initial studies of human subjects. Subsequent human studies were carried out with lots $\mathrm{DN}-6$ to $\mathrm{DN}-13$. As a means of bioassay, the clearance from the blood of trace amounts $(0.025 \mathrm{mg}$ per $\mathrm{kg}$ body weight) of each lot was determined in normal volunteers. The first preparation (DN-4) showed a delayed clearance of the trace dose. Subsequently, the method of preparation of the colloid was modified, and lots DN-6 through DN-13 gave consistent results. It must be emphasized that although reproducibility can be obtained when adequate care is taken in the preparation of the colloidal material, control studies of the clearance rate in normal man are

2 We are grateful to the Squibb Laboratories, in particular to Dr. Howard Stern, for providing the labeled aggregated albumin without charge and for helpful consultations. 
necessary to avoid errors in interpretation of the results obtained in diseased patients. Furthermore, it is important to test each new preparation of both radioactive and carrier aggregated albumin to be certain that the rate of clearance of the material is in the proper range.

The colloidal material was unchanged in its physiological behavior during 8 months of storage at $4^{\circ} \mathrm{C}$.

Measurement of the rate of clearance of aggregated albumin from the blood. Doses of labeled aggregated albumin ranging from 0.025 to $20.0 \mathrm{mg}$ per $\mathrm{kg}$ were injected into 22 dogs and 25 normal subjects ( 38 determinations and 98 determinations, respectively). Thyroidal uptake of radioiodine was blocked by prior administration of 0.5 to $1.0 \mathrm{ml}$ of Lugol's solution. At intervals ${ }^{3}$ after intravenous administration of the albumin, blood samples were taken from the femoral artery of anesthetized dogs or from the antecubital vein of human subjects. The radioactivity of $1-\mathrm{ml}$ plasma samples was determined using a well-type scintillation detector. The plasma was then passed through a resin column (containing $3 \mathrm{ml}$ of Amberlite IRA-400, chloride form) to remove free iodide that had been liberated by metabolic activity of the reticuloendothelial cells. The plasma was washed out of the resin bed with distilled water to yield a final volume of $10 \mathrm{ml}$. After the free iodide had been removed, the radioactivity of the plasma was again measured, a correction being made for the variations in counting geometry produced by increasing the volume from 1 to $10 \mathrm{ml}$. Throughout these studies, the halftime $\left(t_{1}\right)$ of clearance of aggregated albumin from plasma is defined as the time in minutes required for the counting rate to fall to half of the value obtained at two minutes after injection of aggregated albumin in the dog, and to half the value at five minutes after injection in human subjects. In the dog, the two-minute period was considered adequate to allow thorough mixing in the vascular system. Five minutes was allowed for mixing to occur in normal man. Clearance rate determinations were made from measurements of the aggregated albumin only after the free iodide had been removed by the resin technique.

\section{RESULTS}

Blood clearance of $I^{131}$-labeled aggregated albumin. In Figure 2, plasma radioactivity is plotted as a function of time after intravenous injection of trace doses $(0.025 \mathrm{mg}$ per $\mathrm{kg}$ ) of colloidal albumin in dogs. As indicated by the solid line, the total plasma radioactivity fell rapidly with a clearance rate of $29.6 \%$ per minute. About 12 minutes after injection, the plasma radioactivity began to rise again, the secondary rise being produced by the appearance of free iodide in the circulation. To prove that the reappearance of the radioiodine

$32,5,8$, and 11 minutes after injection in dogs and 5, $7,10,15$, and 20 minutes after injection in man.

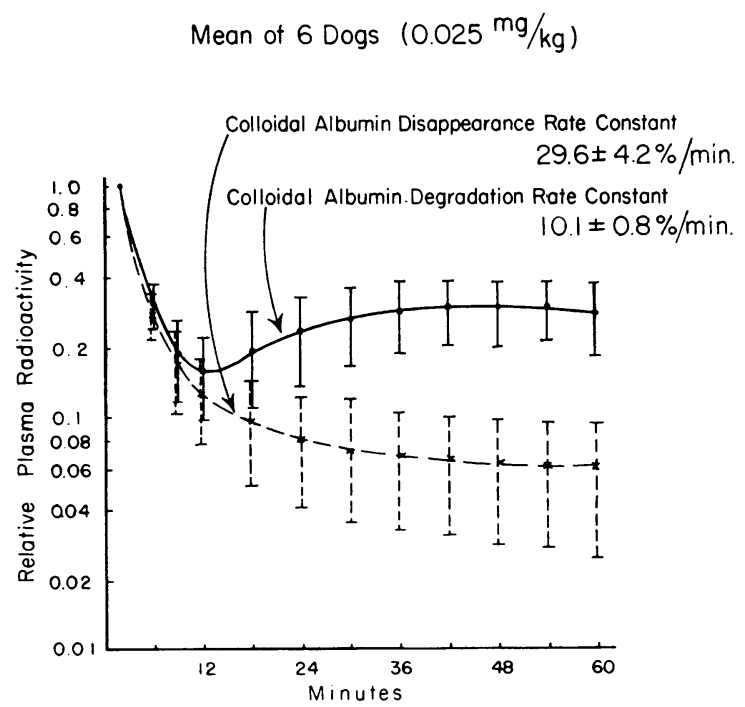

Fig. 2. Blood Clearance of AGgregated albumin in NORMAL DOGS. The solid line indicates total plasma radioactivity, and the broken line indicates the radioactivity of plasma after removal of free iodide.

was in the form of iodide ion, we measured the rate of accumulation of radioiodine by the thyroid of normal men 2 and 24 hours after the administration of the labeled colloidal albumin and found the thyroid uptake to be within the range obtained in normal persons after oral radioactive iodide administration. Presumably the rate of deiodination of the labeled aggregated albumin was of the same order of magnitude as the absorption of an oral iodide dose. In all other studies, radioiodine accumulation by the thyroid was blocked by the prior administration of Lugol's solution.

If one measured only the radioactive aggregated albumin by removing the free iodide prior to determination of the plasma radioactivity, one observed a continual fall in the radioactivity, indicated in Figure 2 by the broken line. These experiments illustrated the rapid clearance of the aggregated albumin followed by the reappearance of free iodide in the circulation, presumably the result of the metabolic activity of the reticuloendothelial system.

Figure 3 illustrates that as the dose of aggregated albumin was increased from 0.025 to $20 \mathrm{mg}$ per $\mathrm{kg}$, there was a progressive decrease in the rate of clearance of the colloid from the blood. As shown in the data of Table II, the half-time of disappearance of the colloidal albumin from the blood increased as the dose increased. 


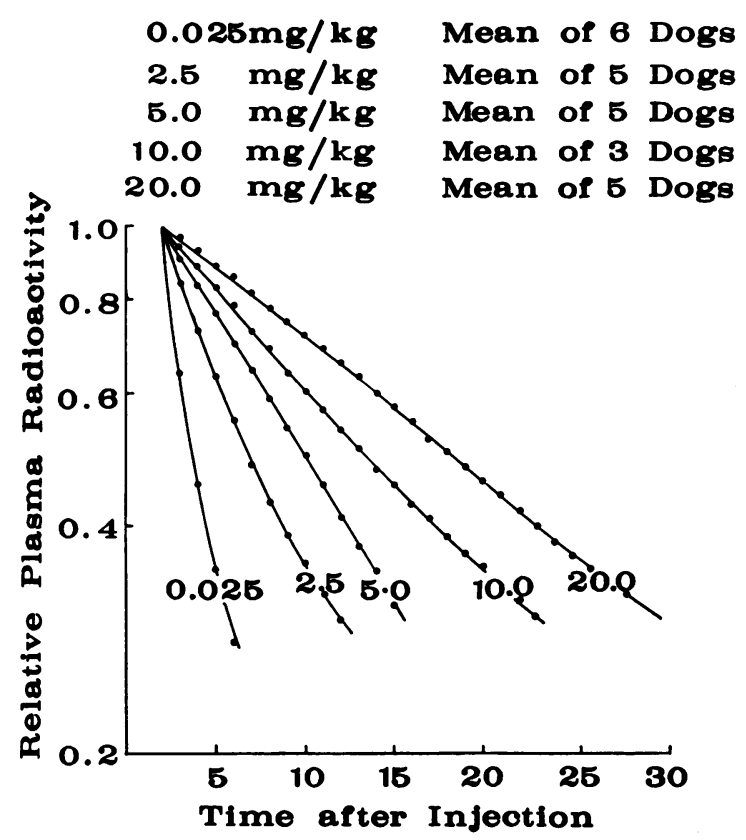

Fig. 3. Blood Clearance at doses of $0.025,2.5,5.0$, 10.0, AND 20.0 MG PER KG OF AGGREGATED ALbUMIN IN NORMAL DOGS.

In both man and dog, measurement of the relationship between the administered dose of aggregated albumin particles and their rate of disappearance from the circulation permitted us to determine the maximal rate of removal of these particles from the circulation. This maximal rate, termed by us the "phagocytic capacity of the RES," has been calculated according to the analysis described by Michaelis and Menten in 1913 (7) and extended by Lineweaver and Burk in 1934 (8).

TABLE II

Blood clearance of aggregated albumin in man

\begin{tabular}{|c|c|c|c|c|c|}
\hline $\begin{array}{l}\text { Amount of } \\
\text { colloidal } \\
\text { albumin } \\
(A A)\end{array}$ & Studies & $\begin{array}{l}\text { Half- } \\
\text { time of } \\
\text { blood } \\
\text { clear- } \\
\text { ance }\end{array}$ & $\begin{array}{l}\text { Relative } \\
\text { standard } \\
\text { deviation }\end{array}$ & $\begin{array}{c}\text { Fractional } \\
\text { clearance } \\
k_{1}\end{array}$ & $\begin{array}{c}\text { Clearance } \\
\text { rate } \\
k_{1}(A A)\end{array}$ \\
\hline $\mathrm{mg} / \mathrm{kg}$ & no. & $\min$ & $\%$ & $\min ^{-1}$ & $\underset{\min }{\mathrm{mg} / \mathrm{kg} /}$ \\
\hline 0.025 & 16 & 2.6 & 19.2 & 0.267 & 0.007 \\
\hline 1.0 & 5 & 3.1 & 12.9 & 0.226 & 0.226 \\
\hline 2.0 & 5 & 4.2 & 14.3 & 0.164 & 0.328 \\
\hline 4.0 & 5 & 4.9 & 20.4 & 0.142 & 0.568 \\
\hline 5.0 & 49 & 5.9 & 11.9 & 0.117 & 0.585 \\
\hline 6.0 & 5 & 6.8 & 5.9 & 0.102 & 0.612 \\
\hline 8.0 & 6 & 7.6 & 17.1 & 0.091 & 0.731 \\
\hline 10.0 & 7 & 9.1 & 20.9 & 0.076 & 0.760 \\
\hline
\end{tabular}

Mathematical analysis. When small doses of aggregated albumin were administered, the effect of variations in dose on the rate of clearance of the particles from the circulation was marked, whereas at higher doses, an increased dose had much less effect on the rate of removal. In terms of Michaelis-Menten kinetics, we can postulate the following reaction between the aggregated albumin particles $(A A)$ and the RES.

$$
A A+R E S \underset{k 2}{\stackrel{k 1}{\rightleftarrows}}(A A \cdot R E S) \stackrel{k 3}{\rightarrow} \text { products + RES, }
$$

where $k_{1}, k_{2}$, and $k_{3}$ are the unidirectional velocity constants. In the case of the aggregated albumin particles, $k_{2}$ is assumed to be zero, since there is no evidence that the aggregated particles are returned as such to the circulation.

According to the Michaelis-Menten equation:

$$
v=\frac{k_{3}(A A)(R E S)}{K_{m}+(A A)},
$$

where $v=$ initial velocity of the reaction and $K_{m}$, the Michaelis constant, equals $\left(k_{2}+k_{3}\right) / k_{1}$. In our system, since $k_{2}$ can be assumed to be zero, $K_{m}=k_{3} / k_{1}$. Therefore:

$$
v=\frac{k_{3}(A A)(R E S)}{k_{3} / k_{1}+(A A)} \text {. }
$$

As the dose of aggregated albumin approaches infinity, from Equation 3

$$
v \rightarrow v_{\max }=k_{3}(R E S) \text {. }
$$

Substituting $v_{\max }$ into Equation 3,

$$
v=\frac{v_{\max }(A A)}{k_{3} / k_{1}+(A A)} .
$$

Rearranging terms, according to the method of Lineweaver and Burk, one obtains

$$
\frac{1}{v}=\frac{k_{3} / k_{1}}{v_{\max }} \cdot \frac{1}{(A A)}+\frac{1}{v_{\max }} .
$$

If one plots $1 / v$ against $1 /(A A)$, a linear relationship is obtained, the line having a slope of $\left(k_{3} / k_{1}\right) / v_{\max }$ and an intercept of $1 / v_{\max }$. Thus one can obtain the value of $v_{\max }$ from the value of the intercept obtained graphically.

According to the so-called "steady state" of the Michaelis-Menten analysis, $v=k_{1}(A A)=k_{3}$ $(A A \cdot R E S)$, that is, with large doses the rate of 
removal of the particles from the circulation is equal to the rate of breakdown of the AA particles in the RES.

Thus, the velocity, $v$, is determined by measuring the time required for the plasma radioactivity to reach a value half that obtained five minutes after injection in man and two minutes after injection in the $\operatorname{dog}$ (see Methods). Since $v=$ $k_{1}(A A)$, then our final equation for the graph suggested by Lineweaver and Burk becomes

$$
\frac{1}{k_{1}(A A)}=\frac{k_{3} / k_{1}}{v_{\max }} \cdot \frac{1}{(A A)}+\frac{1}{v_{\max }}
$$

(A)

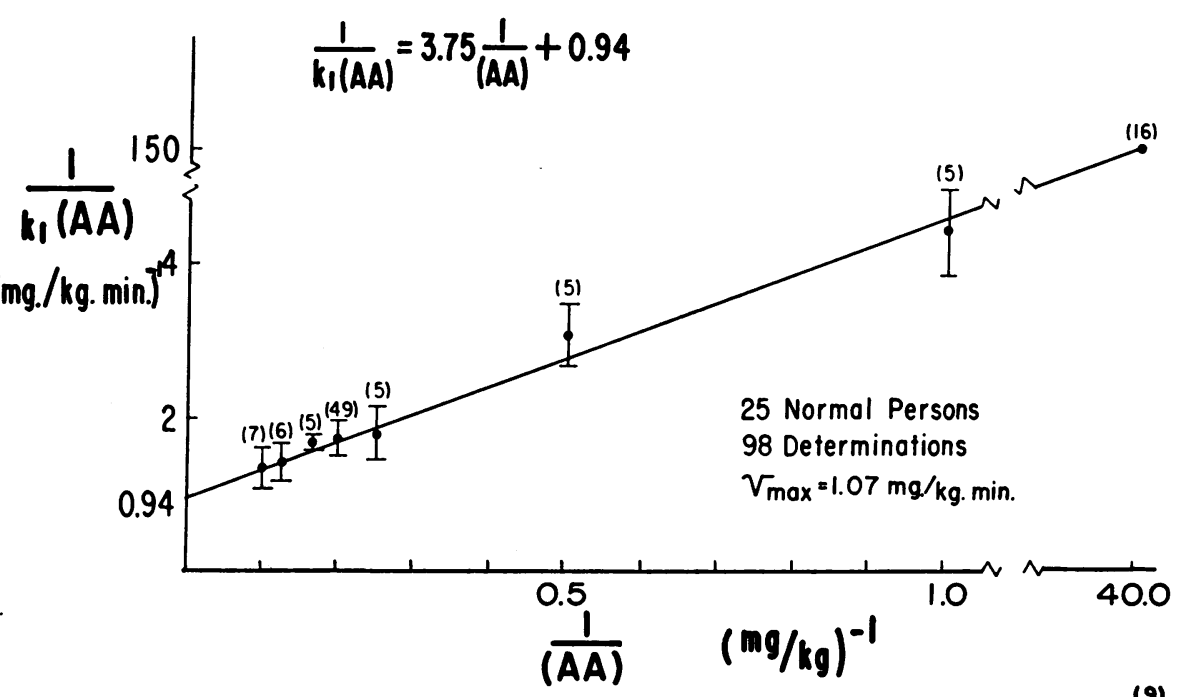

(B.)

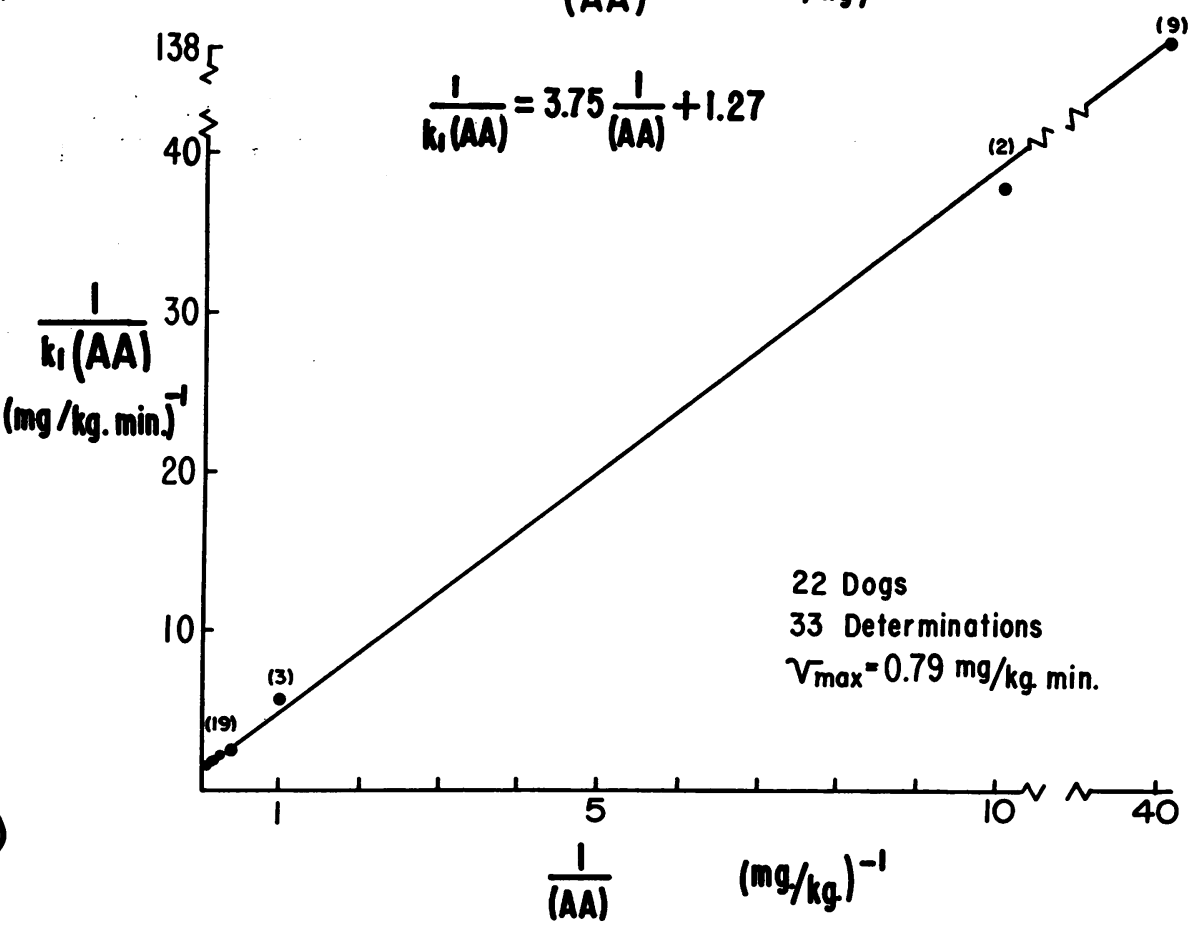

Fig. 4. LiNeweaver-BurK GRAPHS OF THE DOUBLE-RECIPROCAL RELATIONSHIP BETWEeN THE ADMINISTERED DOSE OF AGGREGATED ALBUMIN AND THE RATE OF REMOVAL OF THE PARTICLES FROM THE circulation. A. Results obtained in nORMal PERSONs. The intercept is the reciprocal of the maximal rate of clearance of particles by the RES. B. RESUlts obTAINED IN DOGS. Table III lists values \pm standard deviations. The numbers in parentheses are the number of observations. The standard deviation of the value $1 / k_{1}(A A)=149$ was \pm 29 . 
TABLE III

Blood clearance of aggregated albumin in dog

\begin{tabular}{cccccc}
\hline \hline $\begin{array}{c}\text { Amount of } \\
\text { colloidal } \\
\text { albumin } \\
(A A)\end{array}$ & Dogs & $\begin{array}{c}\text { Half- } \\
\text { time of } \\
\text { blood } \\
\text { clear- } \\
\text { ance }\end{array}$ & $\begin{array}{c}\text { Relative } \\
\text { standard } \\
\text { deviation }\end{array}$ & $\begin{array}{c}\text { Fractional } \\
\text { clearance } \\
k_{1}\end{array}$ & $\begin{array}{c}\text { Clearance } \\
\text { rate } \\
k_{1}(A A)\end{array}$ \\
\hline$m g / k g$ & no. & min & $\%$ & min-1 & $\begin{array}{c}\text { mg/kg/ } \\
\text { min }\end{array}$ \\
0.025 & 9 & 2.4 & 10.8 & 0.289 & 0.007 \\
0.1 & 2 & 2.6 & 0.4 & 0.266 & 0.027 \\
1.0 & 3 & 3.9 & 4.1 & 0.178 & 0.178 \\
2.5 & 5 & 4.6 & 11.5 & 0.151 & 0.375 \\
4.0 & 2 & 6.1 & 9.3 & 0.114 & 0.455 \\
5.0 & 5 & 7.6 & 2.6 & 0.091 & 0.456 \\
6.0 & 4 & 7.2 & 37.1 & 0.096 & 0.577 \\
10.0 & 3 & 11.5 & 29.0 & 0.060 & 0.600 \\
\hline
\end{tabular}

Determination of the maximal rate of phagocytosis of aggregated albumin in normal man and dog. Figure $4 \mathrm{~A}$ and $\mathrm{B}$ illustrates the doublereciprocal plot relating the dose of aggregated albumin particles and their rate of removal from the circulation of normal man and dog, respectively. To obtain the velocity constant, $k_{1}$, we plotted plasma radioactivity as an exponential rather than linear function of time. This made possible determination of $k_{1}$ from the relationship $k_{1}=\ln 2 / t_{1}$. The nearly exponential rate of decrease of plasma radioactivity over the period of at least one half-time (Figure 3) made this possible, and facilitated further handling of the data.

In man, the value, $v_{\max }$, the maximal rate of phagocytosis of the particles, was $1.07 \mathrm{mg}$ per $\mathrm{kg}$ per minute. In the dog, the maximal rate was $0.79 \mathrm{mg}$ per $\mathrm{kg}$ per minute.

These values were obtained by graphing the half-time of clearance $\left(t_{\frac{1}{2}}\right)$ of the various doses of particles against the administered dose $(A A)$. The equation of the straight line that was obtained is

$$
t_{\xi}=a \cdot(A A)+b .
$$

We thus obtained the values of $a$ and $b$ for substitution in Equation 9,

$$
k_{1}(A A)=\frac{0.693(A A)}{a(A A)+b},
$$

which is derived from [8]. In man, $a=0.65$, $. b=2.6$; in the $\operatorname{dog}, a=0.88, b=2.6$. The limiting value that $k_{1}(A A)$ approaches as the dose $(A A)$ approaches infinity, equal to $0.693 / a$, can be shown algebraically to be identical to $v_{\max }$ .obtained from the Michaelis-Menten analysis, since $a=0.693 / v_{\max }$ and $b=\left(0.693 / k_{3} / k_{1}\right) / v_{\max }$. However, it is more accurate to determine Equation 8 rather than Equation 7 by the method of least squares. The latter gives undue importance to the clearance of the dose of $0.025 \mathrm{mg}$ per $\mathrm{kg}$.

Similarly, an alternate method of graphing the data is to plot the rate of removal of aggregated albumin particles, $k_{1}(A A)$, as a function of the dose. As shown in Figure $5 \mathrm{~A}$ and $\mathrm{B}$, as the dose increased, the rate approached a limiting value in both man and dog. This limiting value indicated the maximal rate of removal of these particles from the circulation of normal human subjects and dogs, respectively.

Immunological studies. Because of the possibility that the aggregated albumin might be antigenic to man, certain immunological studies were performed. One indication of a lack of hypersensitivity developing to homologous aggregated albumin was the fact that no change was observed in the rate of clearance of aggregated albumin from the circulation of a normal subject given multiple injections over a 24-day period. Table IV also lists data obtained in two normal subjects given successive doses of $5 \mathrm{mg}$ per $\mathrm{kg}$ at 24-hour intervals. Again no significant change in clearance rate was observed.

Six subjects who received multiple injections of colloidal albumin over a two-week period were subsequently tested with intradermal injections of aggregated albumin. None showed any cutaneous reaction at 48 hours; one positive reaction was observed at 24 hours after the intradermal in-

TABLE IV

Serial measurement of the clearance of aggregated albumin in man

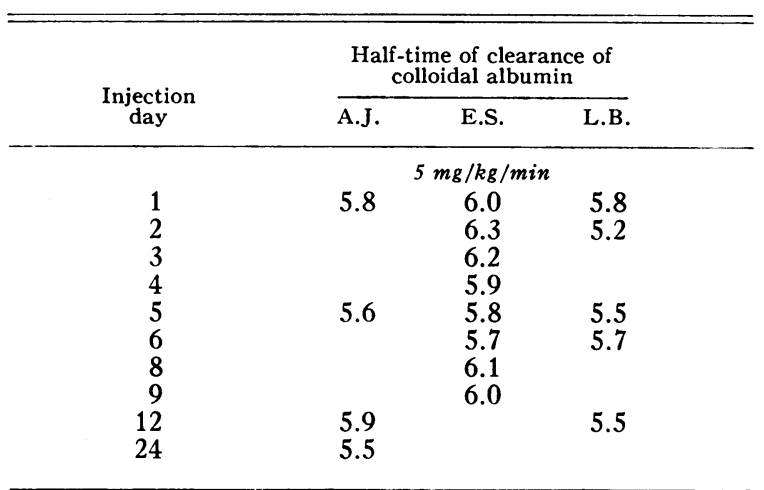


jection of $0.1 \mathrm{ml}$ of $3 \%$ colloidal albumin solution. By 48 hours, however, the skin test had become negative. Ouchterlony precipitin tests (9) and passive cutaneous anaphylaxis (PCA) tests (10) were performed with the plasma of three human subjects, including the one subject who had shown a positive skin reaction at 24 hours. The Ouchterlony precipitin test revealed no precipitation bands or halos in any of the human sub- jects. Although repeated injections of human aggregated albumin to dogs resulted in both generalized anaphylactic and strongly positive PCA reactions, all patients had negative PCA tests and were asymptomatic, even after repeated doses over a six-week period.

Additional data indicating a lack of antigenicity of aggregated albumin in man was the finding that the clearance rate of trace doses of $\mathrm{I}^{131}$-labeled

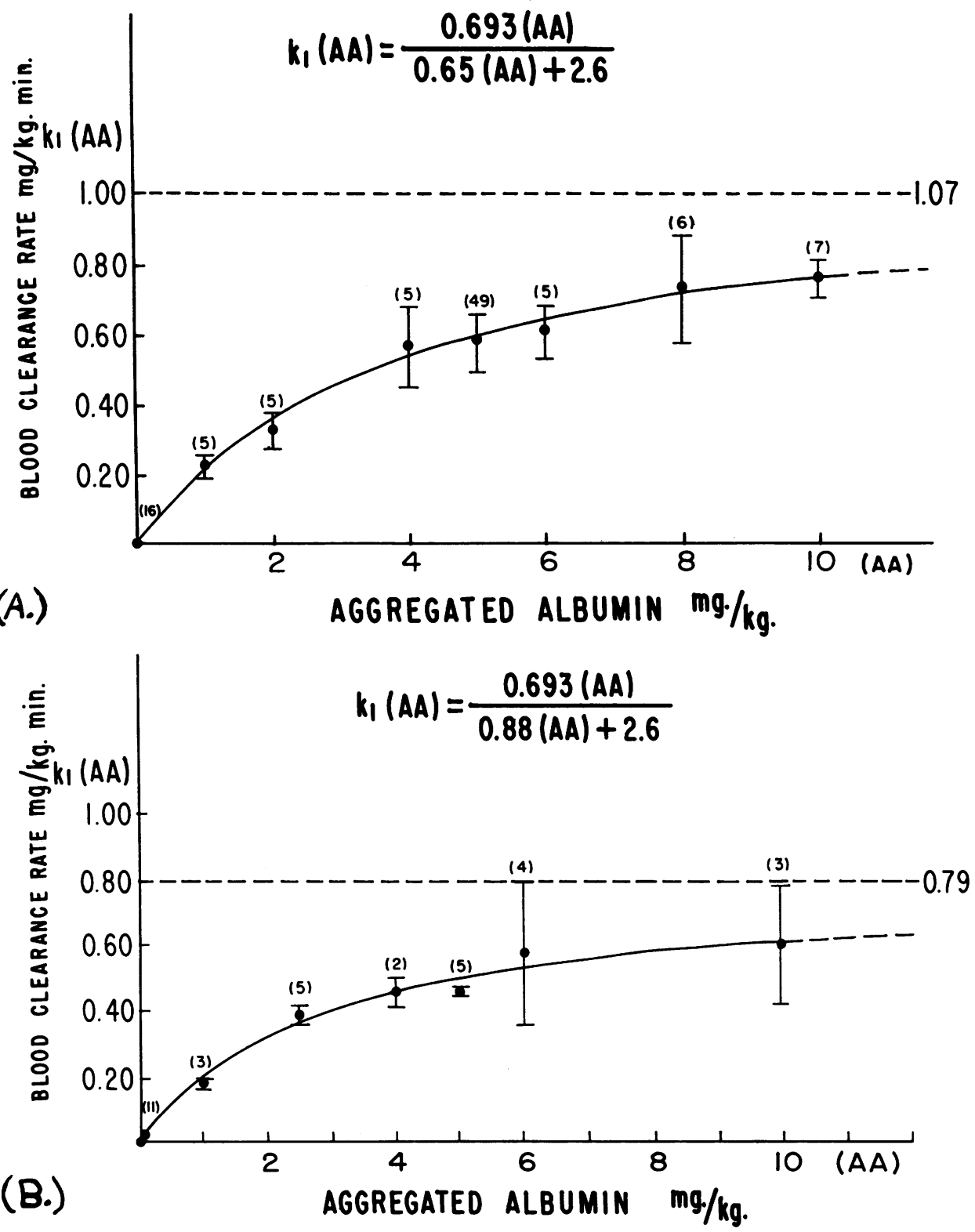

Fig. 5. Relationship between the dose of aggregated albumin and the RAte of ClearANCE OF THE PARTICLES FROM THE BLOOD (MILligRAMS PER MINUTE PER KILOGRAM OF BODY WEIGHT) IN MAN (A) AND DOG (B). 
Degradation of Iodinated Human Serum Albumin

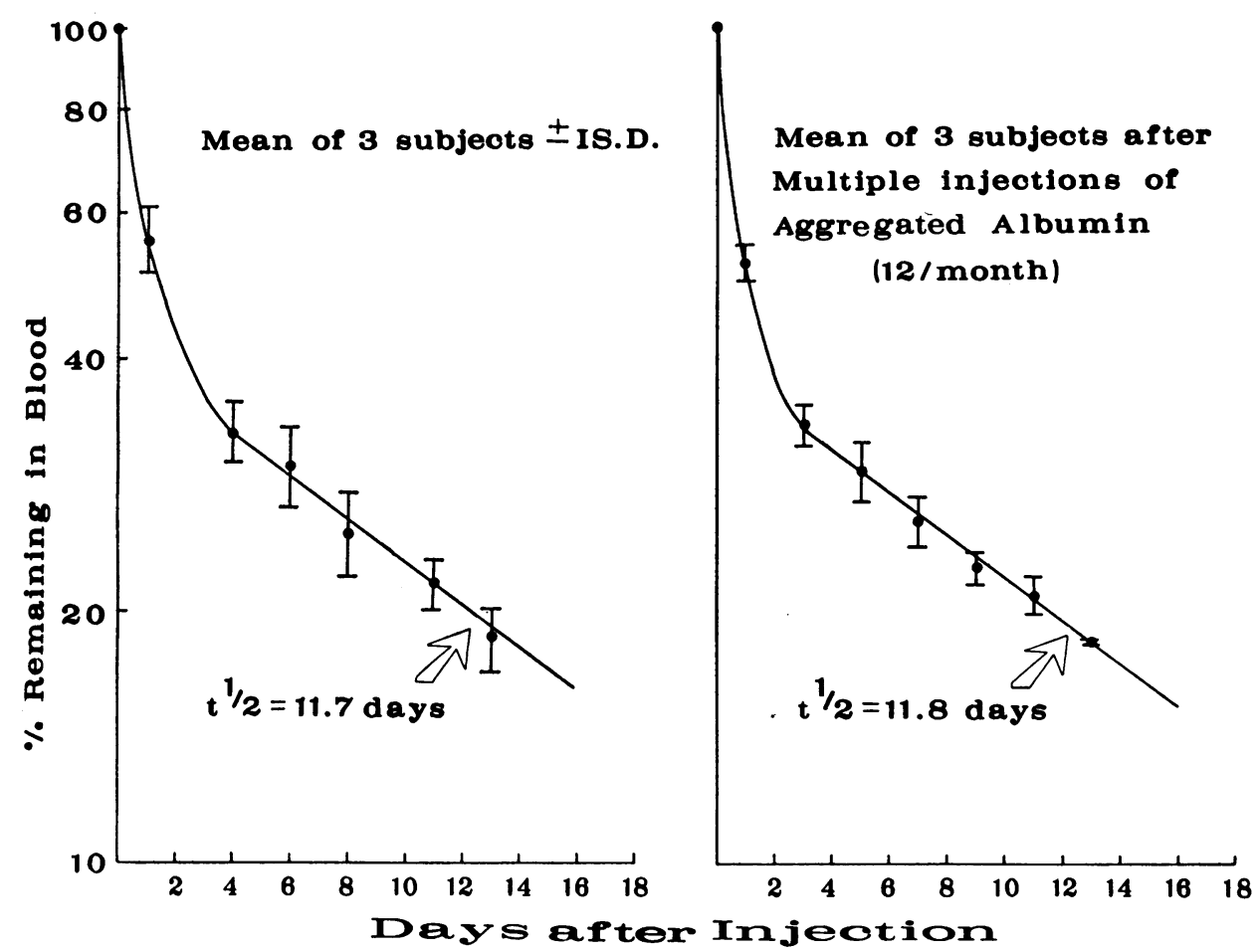

Fig. 6. The Clearance Rate of trace doses of I ${ }^{181}$-LABEled NORMal SERUm albumin in SUbJECTS AFTER MULTIPLE INJECTIONS OF AGGREGATED ALBUMIN COMPARED TO CONTROL SUBJECTS.

normal serum albumin in three subjects who had received multiple injections of $5 \mathrm{mg}$ per $\mathrm{kg}$ aggregated albumin over a two-month period was identical to the rate of disappearance of labeled albumin from the circulation of subjects who had never received injections of the aggregated albumin (Figure 6) (11).

Radiation dosimetry. Another safety consideration was the associated radiation to the patient. The radiation that the patient receives from a dose of $10 \mu \mathrm{c}$ of radioiodinated aggregated albumin is 0.002 rads. The low dose is the result of the rapid release of radioiodine from the reticuloendothelial cells with subsequent excretion in the urine. Thus, the exposure to radiation is well within permissible limits, the dose being far less than is received during a single roentgenogram of the chest.

\section{DISCUSSION}

In the present study, we have found that aggregated albumin particles labeled with radioactive iodine can be safely administered to human sub- jects in amounts large enough to permit measurement of the phagocytic capacity of the RES. Our data can be analyzed according to the method developed by Michaelis and Menten to measure the concentration of an enzyme by determining the rate of disappearance of substrate. In the present system, the aggregated albumin particles are analogous to substrate and the RES analogous to enzyme. In using the term RES, we do not mean to imply a specific type of mesenchymal cell. For our purposes, the RES is defined as all factors participating in the phagocytosis of aggregated albumin. For example, it is possible that the particles react with some humoral factor prior to phagocytosis, and that our data describe the reaction with this substance rather than the RE cells themselves.

In addition to the experimental results that we have obtained, when we graphed the published data of Benacerraf and his associates using various experimental animals and different colloidal particles $(3,4,13-15)$, a similar relationship between the administered dose of colloid and the 
TABLE V

Comparison of present method and Benacerraf's method of measuring functional capacity of RES

\begin{tabular}{|c|c|c|c|c|}
\hline \multirow[b]{2}{*}{ Species } & \multirow[b]{2}{*}{ Colloidal material } & \multicolumn{3}{|c|}{ Functional capacity of RES } \\
\hline & & $\begin{array}{r}k_{1}(A \\
\operatorname{Lim}(A)\end{array}$ & 1) $\rightarrow \infty$ & $\begin{array}{c}\text { Benacerraf method } \\
k D=\text { constant }\end{array}$ \\
\hline Mouse & $\begin{array}{l}\text { Carbon particle } \\
\text { Colloidal serum } \\
\text { protein } I^{\mathbf{1 3 1}} \\
\text { Colloidal albumin } \mathbf{I}^{\mathbf{1 3 1}}\end{array}$ & $\begin{array}{l}4.22^{*} \\
2.13^{*} \\
2.31 \dagger\end{array}$ & $m g / k g / m i n$ & $\begin{array}{l}4.08 \\
2.00 \\
2.30\end{array}$ \\
\hline Rat & $\begin{array}{l}\text { Carbon particle } \\
\text { Colloidal albumin } \mathbf{I}^{131} \\
\text { Colloidal iron }\end{array}$ & $\begin{array}{l}1.89 \dagger \\
1.76^{*} \\
0.20^{*}\end{array}$ & & $\begin{array}{l}2.08 \\
1.25-1.55 \\
0.20\end{array}$ \\
\hline Rabbit & $\begin{array}{l}\text { Carbon particle } \\
\text { Colloidal albumin } I^{131}\end{array}$ & $\begin{array}{l}0.80^{*} \\
0.48-0\end{array}$ & $77 \dagger$ & $\begin{array}{l}0.73 \\
0.45-0.64\end{array}$ \\
\hline Guinea pig & $\begin{array}{l}\text { Carbon particle } \\
\text { Colloidal albumin } I^{131}\end{array}$ & $1.22 \dagger$ & & $\begin{array}{l}1.70 \\
1.15\end{array}$ \\
\hline
\end{tabular}

* Plotted according to Lineweaver-Burk.

$\uparrow$ Plotted according to Equation 8.

rate clearance could be demonstrated even with doses as high as $500 \mathrm{mg}$ per $\mathrm{kg}$. The blood clearance rate approached a limiting rate as the dose increased. This limiting rate which we have called the phagocytic capacity of the RES was the maximal rate at which the RES could phagocytize the colloidal preparation, regardless of the amount of colloid administered.

After studying the rate of clearance of colloids in experimental animals, Benacerraf and his associates concluded that one must inject extremely large quantities of colloidal particles to study the RES. This conclusion was based on their observations that, as the number of administered particles was increased, a point was reached at which the product of the dose and the fractional clearance became constant $(13,14,15)$. In studies of human beings, one cannot safely administer suffciently large doses of colloid to make the clearance rate constant. For example, if one wished to inject aggregated albumin as a $3 \%$ solution to a person with a body weight of $60 \mathrm{~kg}$, our results indicate that one would have to inject $150 \mathrm{ml}$ of the aggregated albumin solution to measure the capacity of the RES by Benacerraf's method. Fortunately, this is not necessary. We have shown that the limiting rate of clearance of colloids by the RES can be determined by administering several intermediate doses of colloid and measuring their respective half-times of clearance from the blood. As seen in Table $\mathrm{V}$, recalculation of the data of Benacerraf by our method gives nearly identical values of RES capacity as were obtained by the administration of single extremely large doses of colloid. Similar results were obtained whether we plotted the data of Benacerraf according to Lineweaver-Burk or according to Equation 8.

Other indices of RES function have been used. One may measure the clearance rate constant of a single large dose of colloidal albumin to obtain an indication of the capacity of the RES. This is not completely satisfactory because of the influence of variability in blood flow under certain conditions, such as in cirrhosis of the liver. To correct for blood flow, Taplin suggested dividing the clearance rate constant of a large dose of albumin by the clearance rate constant of a very small dose, i.e., $0.025 \mathrm{mg}$ per $\mathrm{kg}(16)$. In our opinion, this "corrected phagocytic index" is still too greatly influenced by variations in blood flow. In other words, blood flow variations dilute information about RES efficiency, the measurement of which is our primary objective.

The data in Table $\mathrm{V}$ indicate that the absolute units of the functional capacity of the RES depend on the type of colloidal particle used to measure its capacity. In each animal species examined, there was considerable variation in the dose of various colloids required to saturate the RES. For example, a larger dose of carbon was required than of aggregated protein. Similarly, much less colloidal iron was required when compared to carbon particles. However, regardless of the particle used, the RES of the rabbit had a smaller capacity for colloidal particles than did other spe- 
cies. This observation is consistent with the fact that the liver of the rabbit has relatively fewer RE cells than liver of the rat (17).

\section{SUMMARY}

1) When human serum albumin is aggregated under standardized conditions, a polymer is obtained that can be successfully used to study the phagocytic capacity of the reticuloendothelial system (RES) in man.

2) In addition to careful control of $\mathrm{pH}$, temperature, amount of agitation, and concentration of the albumin solution, it is necessary to monitor the changes in optical density, to insure adequacy of the prepared material by bioassay in man, or dog, or both, and to conduct simultaneous control studies in normal subjects during the study of patients.

3) Large doses of aggregated albumin can be safely administered over prolonged periods to human subjects without evidence of hypersensitivity or excessive radiation.

4) The phagocytic capacity of the RES in both man and dog was determined experimentally with the analytical method of Michaelis and Menten. In man, this maximal rate of phagocytosis of aggregated albumin was $1.07 \mathrm{mg}$ per minute per $\mathrm{kg}$ of body weight.

\section{REFERENCES}

1. Metchnikoff, E. In l'immunité dans les maladies infectieuses. Paris, Masson, 1901.

2. Aschoff, L. Das reticulo-endotheliale System. Ergebn. inn. Med. kinderheilk. 1924, 26, 1.

3. Benacerraf, B., B. N. Halpern, C. Stiffel, S. Cruchaud, and G. Biozzi. Phagocytose d'une fraction du serum chauffé et iodé par le système reticuloendothelial et comportement consecutif de ses cellules à l'égard d'autres colloides. Ann. Inst. Pasteur, 1955, 89, 601.

4. Benacerraf, B., G. Biozzi, B. N. Halpern, C. Stiffel, and D. Mouton. Phagocytosis of heat denatured human serum albumin labelled with I-131 and its use as a means of investigating liver blood flow. Brit. J. exp. Path. 1957, 38, 35.

5. Taplin, G. V., M. L. Griswold, and E. K. Dore. Preparation of colloidal suspensions of human serum albumin I-131 for estimating liver blood flow and reticuloendothelial system functions in man. UCLA report 481 (Biology and Medicine), June, 1961.

6. Method of Squibb Laboratories. New Brunswick, N. J.

7. Michaelis, L., and M. L. Menten. Die Kinetik der Invertinwirkung. Biochem. Z. 1913, 49, 333.

8. Lineweaver, H., and D. Burk. The determination of enzyme dissociation constants. J. Amer. chem. Soc. 1934, 56, 658.

9. Ouchterlony, O. Diffusion-in-gel methods for immunological analysis. Progr. Allergy 1958, 5, 1.

10. Ovary, Z. Immediate reactions in the skin of experimental animals provoked by antibody-antigen interaction. Progr. Allergy 1958, 5, 459.

11. Talmage, D. W., F. J. Dixon, S. C. Bukantz, and G. J. Dammin. Antigen elimination from the blood as an early manifestation of the immune response. J. Immunol. 1951, 67, 243.

12. Wagner, H. N., Jr., M. Iio, and R. B. Hornick. Studies of the reticuloendothelial system. II. Changes in the phagocytic capacity of the RES in patients with certain infections. J. clin. Invest. 1963, 42, 427.

13. Biozzi, G., B. Benacerraf, and B. N. Halpern. Quantitative study of the granulopectic activity of the RES. Brit. J. exp. Path. 1953, 34, 441.

14. Biozzi, G., B. N. Halpern, B. Benacerraf, and C. Stiffel. Physiology of phagocytosis of particles by the RES in Physiopathology of the Reticuloendothelial System. A Symposium. Oxford, Blackwell Scientific Publications, 1957, p. 52.

15. Benacerraf, B. Quantitative aspects of phagocytosis in Liver Function. A Symposium on Approaches to Quantitative Description of Liver Function. Washington, D. C., American Institute of Biological Sciences, 1958, p. 205.

16. Taplin, G. V., E. K. Dore, D. E. Johnson. Clinical studies of reticuloendothelial functions with colloidal suspensions of human albumin I-131. UCLA report (Biology and Medicine), Sept., 1961.

17. Friedman, M., and S. O. Byers. Pathogenesis of dietary-induced hypercholesteremia in the rabbit. Amer. J. Physiol. 1954, 179, 201. 